\title{
INOVAÇÃO E TECNOLOGIA NAS UNIDADES PRISIONAIS: BRASIL X ESTADOS UNIDOS
}

\author{
J. H. D. CASTRO*, F. T. NEVES, V. H. CAMARGO, A. C. SILVA, M. R. BARROS \\ Universidade Federal de Goiás - Regional Catalão (GO) \\ joaohdc@yahoo.com.br*
}

Submetido 06/07/2016 - Aceito 19/03/2018

DOI: $10.15628 /$ holos.2018.4815

\section{RESUMO}

A utilização de recursos tecnológicos em penitenciárias com objetivo de aumento de segurança e melhor operacionalização tem sido processos recorrentes nos sistemas prisionais de todo mundo. Ações como estas são de fundamental importância para resolução de problemas como superlotação, segurança e diminuição de custos. Detectar os recursos tecnológicos da unidade prisional de Catalão (GO) e comparar à unidade prisional de Graterford, nos Estados Unidos, diz respeito à busca

principal deste estudo. Para realizar a presente pesquisa, adotou-se por meio de entrevistas com servidores públicos uma abordagem qualitativa, exploratório-descritivo. Ficou comprovada a existência de equipamentos inovadores; entretanto se os dados coletados forem comparados com a Penitenciaria de Graterford, ainda apresentam enorme déficit, tanto em números quanto em tecnologia.

PALAVRAS-CHAVE: Estudo de caso, inovação, justiça.

\section{INNOVATION AND TECHNOLOGY IN DETENTION UNITS: BRAZIL X USA}

\begin{abstract}
The use of technological resources in penitentiaries in order to increase safety and better operation has been recurrent cases in prisons worldwide systems. Actions such as these are of fundamental importance for solving problems such as overcrowding, safety and decrease costs. To detect the technological resources of CatalanGO prison unit and compare to the unit prison of Graterford, in the United States, concerns the main
\end{abstract}

pursuit of this study. To accomplish this research was adopted through interviews with public servants a qualitative, exploratory and descriptive approach. It was proved the existence of innovative equipment; however if the data collected are compared with the Graterford Penitentiary, still have huge deficit, both in numbers and in technology.

KEYWORDS: Case study, innovation, justice. 


\section{INTRODUÇÃO}

Dentre as diversas discussões que permeiam a sociedade atual sobre a condição do sistema prisional brasileiro, temas vigentes como superlotação, custos e direitos dos presidiários, além de ações de ressocialização do detento, fazem-se presentes no campo de debate de autoridades e autores concernentes ao tema. Nesse direcionamento, autores como Duarte Junior e Menezes (2016), em seu estudo, dissertaram sobre a perspectiva da inclusão de sistemas eletrônicos nas cadeias, especificamente por monitoramento eletrônico e aplicação de recursos tecnológicos. Essa tem contribuído para oferecer condições de segurança, uma vez que tem sido aplicada com sucesso em outros países.

Como Brasil possui elevada população carcerária, em penitenciárias com situações precárias e em condições de superlotação, tal fato vem contribuindo para o agravamento do fracasso do sistema prisional. A Constituição Federal, Pactos Internacionais, que o Brasil é signatário, e leis Infraconstitucionais, preveem direitos e garantias aos detentos, e estes devem ser respeitados e amparados pelo Estado e pela sociedade (DUARTE JUNIOR; MENEZES, 2016).

Conforme afirma Neto (2014), o sistema penitenciário existe com a finalidade de que esses indivíduos possam ser reintegrados à sociedade. Importante seria que todo o sistema prisional fosse gerido não mais com uma finalidade exclusivamente punitiva, mas também com verdadeira política de ressocialização para seus internos.

O aumento do número de penitenciárias e vagas não é solução para todas as dificuldades as quais vêm sendo enfrentadas por esse sistema. Como proposta de solução, adotam-se tecnologias que contribuem para fiscalização e monitoramento de penitenciárias, cumprimento e execução da pena, dentro e fora dos presídios e, posteriormente, favorecem a reintegração positiva do detento à sociedade. Segundo Duarte Junior e Menezes (2015), a ineficiência do caráter educativo da prisão cautelar, a personalização, a superlotação dos presídios e a ociosidade da população carcerária, o problema da reincidência no sistema carcerário, as facções criminosas no interior dos presídios brasileiros, a exclusão social do acusado, as condições mínimas de higiene e saúde básica são problemas que marcam a crise no sistema penitenciário.

Ainda, nesse sentido, uma ocorrência que vem sendo frequente nas penitenciárias, não apenas do Brasil, mas também dos Estados Unidos, é a entrada ilegal de celulares e objetos para dentro das dependências prisionais; fato, constantemente, visto em estampa nos principais jornais e telejornais brasileiros. Sob esse aspecto, o desenvolvimento de estrutura tecnológica baseada na segurança, tem o poder de influenciar positivamente tal questão que, de uma forma ou de outra, vem desgastando as autoridades responsáveis.

Atualmente, a tecnologia está relacionada a todos os setores da sociedade, inclusive em ações de segurança e bom andamento dos sistemas prisionais. Desse modo, optou-se como busca principal do referido estudo, comparar unidade prisional de Catalão - GO com à penitenciária de Graterford, Pensilvânia, no que diz respeitos à presença de recursos tecnológicos e às entidades responsáveis pela gestão e aplicação dos recursos. 


\section{REFERENCIAL TEÓRICO}

Santana (1992), em suas observações, discorreu sobre o uso de tecnologias a qual está em voga no momento, pois diversos países possuem implantados em seus ordenamentos jurídicos a possibilidade e regulamentação de uso dos mais diversos sistemas tecnológicos. No Brasil, existem Leis que estabeleceram a utilização e regulamentação, outras carecem de regulamentação específica, porque se encontram em fase de testes para ter a sua aplicabilidade confirmada.

Machado (2009) discorre que a utilização de meios alternativos de vigilância sobre detentos tem-se revelado como uma notável alternativa para a fiscalização da execução de penas e cumprimentos de normas penais. No Brasil, o uso de tecnologias dentro dos presídios e o monitoramento eletrônico de detentos à distância por ordem judicial, devem ser utilizados de maneira que não violem direitos fundamentais do acusado ou do detento provisório, e que, ao mesmo tempo, possam ser uma eficiente ferramenta de controle e fiscalização penal.

Duarte Junior e Menezes (2015) salientam que, através do monitoramento eletrônico, o Estado pode oferecer um tratamento mais humano e digno ao encarcerado, aplicando-Ihe uma medida cautelar, como o monitoramento, isso facilitaria o regresso do acusado, posteriormente, à sociedade, mesmo condenado. Neste caso, a função da medida ou da pena possui um caráter mais fidedigno, ou seja, reintegrar o indivíduo à sociedade.

Fabris (2010), em seu trabalho, analisa a fiscalização do detento fora da cadeia pública, dando maior enfoque na humanidade desses indivíduos que estariam a cumprir penas de total privação de liberdade e, com a modernidade, os meios tecnológicos, por exemplo, a tornozeleira eletrônica, que pode dar a localização do detento com razoável precisão em tempo real, contribuindo para a diminuição do problema de superlotação do sistema penitenciário brasileiro.

Corrêa Junior (2012) delineia que a vigilância eletrônica nasce como uma solução para os sistemas carcerários, sendo que o monitoramento do detento e influenciado pela cultura do controle do delito, a busca por alternativas ao modelo antigo do cárcere já e bem antigo e com essas novas alternativas, por si só não irão resolver a redução dos detentos e a reincidência do crime, porém oferecem vantagens econômicas. Essa vigilância eletrônica, ainda, tem como grande função a execução de penas restritivas que substitui o cárcere para delitos menores.

Duarte Junior e Menezes (2015) salientam que, através do monitoramento eletrônico, o Estado pode oferecer um tratamento mais humano e digno ao encarcerado, aplicando-lhe uma medida cautelar, como o monitoramento, isso facilitaria o regresso do acusado, posteriormente, à sociedade, mesmo condenado. Essa vigilância eletrônica, ainda, tem como grande função a execução de penas restritivas que substitui o cárcere para delitos menores.

Assim, o monitoramento eletrônico apresenta uma eficaz fiscalização do indiciado ou do réu, na medida em que permite sua localização imediata através do rastreamento, via satélite. Para Duarte Junior e Menezes (2015), por se tratar de uma medida coercitiva, não seria necessária a permissão do acusado desde que não ocorram constrangimentos. 
Da Silva e Sanchez (2008), detectando um paralelo com os Estados Unidos, observaram que este país não autoriza a utilização de tecnologia de bloqueadores de celular em presídios, prevendo tal atitude como crime, bem como proíbe a interferência maliciosa ou proposital na comunicação via rádio ou qualquer estação autorizada ou licenciada. Os autores ainda afirmam que o sistema americano exerce ainda controles rígidos de fiscalização dentro dos presídios, com funcionários nas entradas e saídas de pessoas, além de priorizar a estratégia de localização dos presídios.

\section{METODOLOGIA}

Severino (1993) descreve que a pesquisa alicerçada no método comparativo procura investigação a respeito coisas e acontecimentos e os analisa conforme igualdade e contrastes e ainda o método de pesquisa comparativa consiste em um planejamento de pesquisa, formulação de hipóteses, coordenação investigativa e interpretação de resultados. Goldenberg (1997), por sua vez, afirma que a pesquisa qualitativa se baseia numa hipótese em que o sujeito analisado e idêntico ao objeto estudado que tem a finalidade de trazer informações, porem se preocupa com apresentação de uma realidade que não pode ser medida.

Para realização do presente estudo adotou-se a abordagem qualitativa do tipo exploratório-descritivo. Como método, escolheu-se o estudo de caso, por se tratar de uma pesquisa que não possuía o escopo de obter generalizações e nem estava preocupada com quantificações e tratamento estatístico de dados, mas sim em entender e compreender em profundidade os casos investigados. Entrevistas foram realizadas na Unidade Prisional de Catalão/GO (UPCat). A amostra foi composta por 3 pessoas com cargos relacionados ao sistema prisional, o Juiz de direito da Comarca de Catalão/GO, responsável pela Vara Criminal e de Execução Penal da cidade, bem como o Promotor de Justiça da 2ㅇo promotoria com atribuição em execução Penal e ainda a Agente de Segurança Prisional, atual supervisora Administrativa da UPCat. Em todos os casos, foram feitos contatos telefônicos prévios, agendadas entrevistas em seus respectivos escritórios e assinado o termo de autorização de uso de depoimento e consentimento livre esclarecido. $O$ estudo se fundamentou também em dados disponíveis nos sites do Governo Estadual, a saber: Superintendência Executiva de Administração Penitenciária (SEAP) e de documentos cedidos pela própria UPCat, como o relatório mensal de informações enviado em abril para a SEAP.

Para a coleta de dados da Penitenciária de Graterford, no estado da Pensilvânia, Estados Unidos, tentou-se contato telefônico, porém o insucesso direcionou a mesma para os dados e informações contidos no site do Departamento de Justiça Americano (do inglês, Department of Justice of The United States).

A escolha das penitenciárias se fez em razão da diferença de porte estrutural das mesmas, sendo a UPCat uma unidade regional e a Penitenciária de Graterford uma prisão de segurança máxima, permitindo o comparativo de dois níveis diferentes. 


\section{RESULTADOS E DISCUSSÕES}

Os autores (SAUNDERS; LEWIS; THORNHILL, 2000) deram como exemplo uma "cebola" para relatarem o processo de pesquisa, em cada uma das camadas faz emergir uma pergunta e uma decisão sobre a linha metodológica que se pretende seguir. Esses ainda discorrem que o processo segue as seguintes "camadas": filosofia de pesquisa, enfoque de pesquisa, estratégia de pesquisa, horizonte de tempo e método de coleta de dados. As três entrevistas realizadas na cidade de Catalão foram comparadas com dados obtidos do departamento de justiça americano e apontaram para o direcionamento das discussões aqui relatadas.

A Figura 1 apresenta a distribuição detentos e o tipo de regime da UPCat em julho de 2016. Tais informações foram obtidas por meio do acesso diretor aos documentos cedidos pela própria unidade prisional. Foi observada uma situação de superlotação da UPCat, uma vez que a capacidade desta era de 176 vagas. Desta forma a unidade prisional estava trabalhando com um excedente de $48 \%$. A Unidade Prisional de Graterford contava com uma capacidade instalada para 4000 detentos do sexo masculino, senda que destas 3100 vagas estavam preenchidas na época da realização da coleta de dados (DEPARTAMENTO DE JUSTIÇA DOS ESTADOS UNIDOS, 2016).

Figura 1: Relação de Gêneros dos detentos/ Tipo de regime da unidade prisional de Catalão - GO.

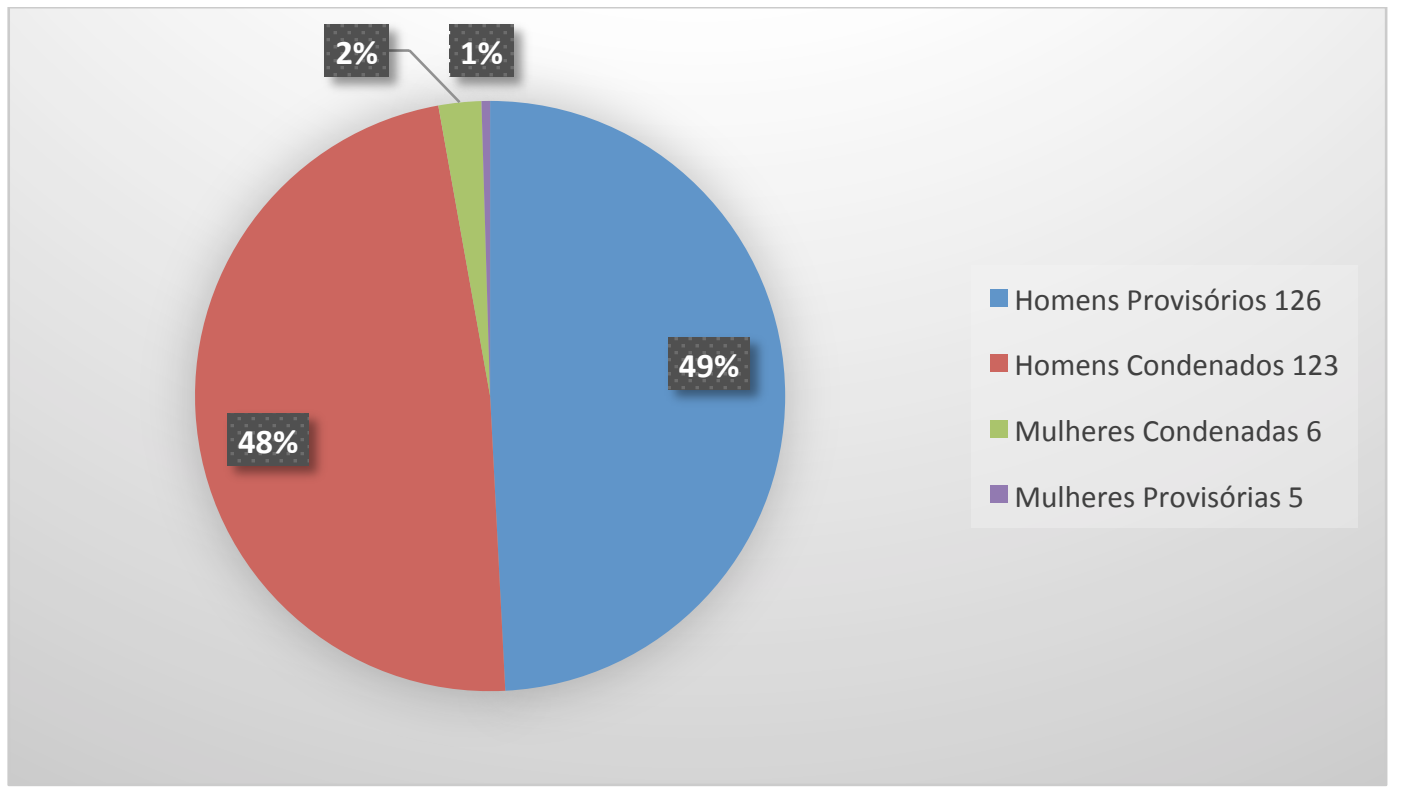

Fonte: Dados obtidos de documentos cedidos pela UPCat.

A relação dos recursos tecnológicos existentes na UPCat foi adquirida a partir da entrevista com a superintendente administrativa da unidade. Com relação aos recursos da unidade de Graterford, a mesma foi obtida no site do Departamento de Justiça dos Estados Unidos. O quadro 1 sintetiza os recursos tecnológicos de ambas unidades prisionais. 
Quadro 1: Recursos Tecnológicos presentes em Catalão (Go) e em Grateford.

\begin{tabular}{l|c|c}
\hline \multicolumn{1}{c|}{ Recursos Tecnológicos } & UPCat & Graterford \\
\hline Cadeira detectora de metais & Sim & Não \\
\hline Detector de metais manual & Sim & Sim \\
\hline Fiscalização por câmeras de segurança & Sim & Sim \\
\hline Identificação de rádio frequência & Não & Sim \\
\hline Maleta rastreadora de celulares & Sim & Não \\
\hline Portal de raios-X & Não & Sim \\
\hline Portal detector de metais & Sim & Sim \\
\hline Tornozeleira eletrônica & Não & Não \\
\hline
\end{tabular}

A maleta de monitoramento de celulares é um dispositivo que rastreia os celulares do perímetro e se conecta aos mesmos em uma situação de "grampo". Quanto aos bloqueadores de celulares, os mesmos foram aplicados durante certo período; contudo a interferência nos aparelhos dos residentes da área ao redor do presídio, fez com que o serviço fosse cancelado pela justiça brasileira. Em contrapartida, com as tornozeleiras eletrônicas, o serviço fora aprovado e solicitado junto à SEAP, porém até o presente momento sem aplicação na UPCat. Uma abordagem potencialmente promissora que envolve tecnologia de identificação de rádio frequência (RFID) vêm sendo desenvolvido pela iniciativa privada nos Estados Unidos, que deverá ser utilizada para o monitoramento de movimentação dos detentos dentro dos presídios (DEPARTAMENTO DE JUSTIÇA DOS ESTADOS UNIDOS, 2016).

Nos Estados Unidos, o órgão responsável pela aplicação de recursos no sistema penitenciário é o Departamento de Justiça Americano, para pesquisa e desenvolvimento foi criado o Instituto Nacional de Justiça (do inglês National Institute of Justice, NIJ). O instituto é dedicado a melhorar o conhecimento e compreensão das questões de crime e justiça por meio da ciência (DEPARTAMENTO DE JUSTIÇA DOS ESTADOS UNIDOS, 2016). No Brasil o Fundo Penitenciário Nacional (FUNPEN), a ser gerido pelo Departamento de Assuntos Penitenciários, da Secretaria dos Direitos da Cidadania e Justiça, com a finalidade de proporcionar recursos e meios para financiar e apoiar as atividades, programas de modernização e aprimoramento do Sistema Penitenciário (DECRETO N. 1.093, 1994). No Estado de Goiás, a aplicação dos recursos deste fundo dá-se pela Secretaria de Estado da Administração Penitenciária e Justiça (SAPeJUS), com suporte da Coordenadoria Interdisciplinar de Pesquisa e Estudos de Execução Penal do Estado de Goiás (Cipepe). Segundo os entrevistados, este sistema de incentivo à ciência e desenvolvimento não fica claro por parte dos gestores e atores do âmbito penitenciário de Catalão/GO, sendo até desconhecida a existência de tais entidades e conselhos responsáveis por tal incentivo, além de desigual aplicação dos recursos junto aos diferentes estados, cidades e unidades prisionais. Este fato aponta o caráter ainda descentralizador da gestão penitenciária, que dificulta a obtenção de recursos perante o FUNPEN, para gestão e desenvolvimento das penitenciárias goianas. Como 
confirma Souza et al. (2015), que observaram a criação em 2002, pelo Governo Marconi Perillo, de uma gestão única de execução penal, em conjunto a criação da Secretaria de Estado da Justiça (SEJUS), atualmente SAPeJUS, para maior captação de recursos federais, ação de cunho centralizador visando maior confiança do Governo federal.

A superioridade do sistema americano pode ser detectada quando se toma conhecimento do Serviço Nacional de Referência em Justiça Criminal (do inglês National Criminal Justice Reference Service, NCJRS). Fundado em 1972, atua como uma biblioteca de banco de dados, com o intuito de oferecer à sociedade americana todo o repertório de informações e desenvolvimento referentes às pesquisas dos programas de justiça, portanto, total transparência dos assuntos de inovação (INSTITUTO NACIONAL DE JUSTIÇA, 2016).

A comparação entre os dois sistemas torna-se inevitável; o americano o mais antigo da sociedade moderna, apresenta, hoje, a maior população carcerária mundial, cerca de 740 detentos para cada 100 mil pessoas e, consequentemente, apresenta desafios maiores em relação à segurança e manutenção do bom andamento da ressocialização dos detentos. Em vista desses fatores, apresentar força e fraquezas, oportunidades e ameaças da implantação de inovações tecnológicas denota-se como uma ação importante para o delineamento da pesquisa. Os Quadros 2 e 3 abaixo apontam a análise SWOT dos dois sistemas, tendo como foco principal a implantação de recursos tecnológicos na UPCat e em Graterford.

Quadro 2: Análise SWOT da UPCat.

\begin{tabular}{|c|c|}
\hline Forças & Fraquezas \\
\hline $\begin{array}{l}\text { Disponibilidade de: Portal, detector manual e } \\
\text { cadeira detectora de metais; } \\
\text { Disponibilidade maleta rastreadora de celulares } \\
\text { Penitenciária de pequeno porte estrutural em } \\
\text { comparação à Graterford; } \\
\text { Pequena quantidade de detentos em comparação } \\
\text { à Graterford; } \\
\text { Estrutura física tecnológica inadequada para } \\
\text { atendimento as necessidades. }\end{array}$ & $\begin{array}{l}\text { Superlotação; } \\
\text { Manutenção e reposição de câmeras de segurança } \\
\text { deficitário; } \\
\text { Inexistência das tornozeleiras; } \\
\text { Inexistência de detector de objetos. }\end{array}$ \\
\hline Oportunidades & Ameaças \\
\hline $\begin{array}{l}\text { Contato e parcerias com Comitês Olímpicos e } \\
\text { Esportivos } \\
\text { Criação da CIPEPE-Coordenadoria Interdisciplinar } \\
\text { de Pesquisa e Estudos de Execução Penal do } \\
\text { Estado de Goiás; } \\
\text { Maior atenção da comunidade científica a respeito } \\
\text { do tema, tecnologia; } \\
\text { Desenvolvimento de novos recursos tecnológicos } \\
\text { em instituições internacionais. }\end{array}$ & $\begin{array}{l}\text { Sistema descentralizado de gestão de } \\
\text { desenvolvimento e aplicação de recursos; } \\
\text { Alto custo de implantação dos sistemas } \\
\text { tecnológicos mais inovadores; } \\
\text { Influência política na aplicação dos recursos; } \\
\text { Incompatibilidade de Leis. }\end{array}$ \\
\hline
\end{tabular}


Quadro 3: Análise SWOT da penitenciária de Graterford.

\begin{tabular}{|c|c|}
\hline Forças & Fraquezas \\
\hline $\begin{array}{l}\text { Disponibilidade de: Portal, detector manual e } \\
\text { cadeira detectora de metais; } \\
\text { Disponibilidade de Portal de raios-X } \\
\text { Eficiente sistema interno de gestão operacional } \\
\text { penitenciária; } \\
\text { Arquitetura e projeções estruturais adequadas à } \\
\text { implantação dos recursos. }\end{array}$ & $\begin{array}{l}\text { Penitenciária de grande porte em comparação à } \\
\text { UPCat; } \\
\text { Grande quantidade de detentos em comparação à } \\
\text { UPCat. }\end{array}$ \\
\hline Oportunidades & Ameaças \\
\hline $\begin{array}{l}\text { Sistema de gestão dos Recursos centralizador; } \\
\text { Criação de institutos de pesquisa e } \\
\text { desenvolvimento, NIJ, NCJRS. }\end{array}$ & $\begin{array}{l}\text { Incompatibilidade de Leis; } \\
\text { Possiblidade de superlotação. }\end{array}$ \\
\hline
\end{tabular}

Uma avaliação baseada nos recursos existentes em ambas penitenciárias e na análise SOWT das mesmas, permitem-nos apontar que a maior necessidade de recursos tecnológicos na unidade se apresenta inversamente proporcional à quantidade de pontos de força e, diretamente proporcional, à quantidade de pontos de fraqueza, no presente contexto. Logo, as forças de Graterford à sustentam com menores necessidades de recursos tecnológicos e as fraquezas da UPCat influenciam a maior necessidade destes. Oportunidades e ameaças dizem respeito ao contexto de mudança deste cenário de precariedade do sistema de Catalão.

\section{CONCLUSÕES}

O estudo ofereceu suporte para analisar o uso da inovação tecnológica na UPCat em comparação com a penitenciária de Graterford. Constatou-se que já existem equipamentos em uso na UPCat, embora alguns dependendo de substituição e/ou reparos e outros que poderiam ser mais avançados, por exemplo, o portal de Raios $X$ que, nas entrevistas, foi citado como próxima aquisição.

Outro fator relevante observado, tanto nos dados coletados, quanto nas entrevistas, foi a superlotação na UPCat, a aquisição de tornozeleiras eletrônicas, poderia melhorar este quadro com o monitoramento e reinserção dos detentos na sociedade foram dos muros da unidade.

Comparando-se a UPCat com a Penitenciária de Gratefort, na Pensilvânia (USA), nota-se a discrepância de recursos tecnológicos entre ambas. O que dá valia a esse estudo é porque se nota a necessidade de maior aplicação de recursos públicos para a tecnologia de inovação na UPCat.

\section{REFERÊNCIAS}

Constituição da República Federativa do Brasil de 1988. Recuperado em 5 de junho, 2016, de http://www.planalto.gov.br/ccivil_03/Constituicao/Constituicao.htm 
Corrêa Junior, A. (2012). Monitoramento eletrônico de penas e alternativas penais (Tese de doutorado). Faculdade de Direito, Universidade de São Paulo, São Paulo, SP, Brasil. Recuperado em 5 de junho, 2016, de http://www.teses.usp.br/teses/disponiveis/2/2136/tde20062013-132709/pt-br.php

Da Silva, A. A. G., \& Sanchez, P. L. P. (2008). Bloqueio de celulares em penitenciárias: um paralelo entre Brasil e EUA. Revista da Faculdade de Direito de São Bernardo do Campo, 14, 45-61. Recuperado em 8 de março, 2018, de https://revistas.direitosbc.br/index.php/fdsbc/article/view/188/137

Decreto n. 1.093 de 23 de março de 1994. Regulamenta a Lei Complementar no 79, de 7 de janeiro de 1994, que cria o Fundo Penitenciário Nacional (FUNPEN), e dá outras providências. Recuperado em 5 de junho, 2016, de http://www.planalto.gov.br/ccivil_03/decreto/19901994/D1093.htm

Departamento de Justiça dos Estados Unidos. Recuperado em 31 de maio, 2016, de http://www.justice.gov

Duarte Junior, A. P., \& Menezes, M. (2015). Monitoramento eletrônico: uma alternativa para crise vivida pelo Sistema Penitenciário Brasileiro. Revista FSA, 12(04), 68-86. Recuperado em 5 de junho, 2016, de http://dx.doi.org/10.12819/2015.12.4.5

Fabris, L. R. (2010). Monitoramento eletrônico de presos. Revista Jus Navigandi, 15(2594). Recuperado em 5 de junho, 2016, de https://jus.com.br/artigos/17136/monitoramentoeletronico-de-presos/3

Goldenberg, M. (1997). A arte de pesquisar. Rio de Janeiro: Record.

Instituto Nacional de Justiça. Recuperado em 25 de maio, 2016, de http://www.nij.gov/Pages/welcome.aspx

Ministério da Justiça. Sistema Prisional Execução Penal » Sistema Prisional » Informações InfoPen. Recuperado em 5 de junho, 2016, de http://portal.mj.gov.br/data/Pages/MJD574E9CEITEMID364AC56ADE924046B46C6B9CC447B 586PTBRIE.htm

Neto, J. A. S. de P. (2014). Ações de Inclusão Digital nas Instituições Penitenciárias do Brasil e da Espanha: um estudo comparado. Revista Informação e Sociedade, 24(03), 65-80. Recuperado em 5 de junho, 2016, de http://www.ies.ufpb.br/ojs/index.php/ies/article/view/18237

Santana, E. J. M. (2015). A utilização de tecnologias no sistema carcerário brasileiro como forma de fiscalização auxiliar no efetivo cumprimento da pena. Jurisway. Recuperado em 5 de junho, 2016, de http://www.jurisway.org.br/v2/dhall.asp?id_dh=14462

Saunders, M., Lewis, P., \& Thornhill, A. (2000). Research methods for business students (2nd ed.). Essex: Pearson Education Ltd.

Severino, A. J. (1993). Metodologia do trabalho científico. São Paulo, SP: Cortez.

Souza, I. C. B. de, Cisse Ba, S. A., Castro, P. A. de, Andrade, M. S., Fritsche, T. R. L., \& Freitas Silva, P. de. (2015, agosto). O perfil sociodemográfico, acadêmico e laboral do agente de segurança prisional de Catalão (GO). Anais do Congresso Ibero-Americano em Investigação Qualitativa, Aracajú, SE, Brasil, 4. Recuperado em 5 de junho, 2016, de https://proceedings.ciaiq.org/index.php/ciaiq2015/article/view/140/136 